\title{
UMA ANÁLISE DOS JOGOS DE NEGÓCIOS COMO ESTRATÉGIA DE ENSINO-APRENDIZAGEM À LUZ DO INTERACIONISMO PELO VIÉS DIALÉTICO
}

\author{
1- Mario Nei Pacagnan* \\ Doutor em Administração pela Universidade de São Paulo (FEA-USP), Brasil. \\ Professor Titular da Universidade Estadual de Londrina (UEL), Brasil. \\ marionei@litzestrategia.com.br \\ http://lattes.cnpq.br/2157501085754464
}

\section{2- Paulo da Costa Lopes}

Doutor em Engenharia de Produção pela Universidade Federal de Santa Catarina (UFSC), Brasil.

Professor Associado da Universidade Estadual de Londrina (UEL), Brasil.

paulocostalopes@gmail.com

http://lattes.cnpq.br/8109140522479826

\section{3- Marcos Rubo}

Mestrando em Administração pela Universidade Estadual de Londrina (UEL), Brasil.

Professor da Secretaria Estadual de Educação do Paraná (SEED), Brasil.

marcos@rubo.com.br

http://lattes.cnpq.br/2453426496220432

\section{4- Valéria da Silva Marques Assis Rubo}

Especialista em Didática e Metodologia do Ensino e em Educação Infantil e Anos Iniciais do Ensino Fundamental pela Universidade Norte do Paraná (UNOPAR), Brasil.

Professora e Pedagoga na Secretaria Estadual de Educação do Paraná (SEED) e na Secretaria Municipal de Educação de Londrina, Brasil.

valeria@rubo.com.br

http://lattes.cnpq.br/2453426496220432

\footnotetext{
* Contato Principal: Rodovia Celso Garcia Cid - PR 445 - KM 380 - Campus Universitário. Londrina - PR, Brasil. CEP:
} 86051-990. Caixa-postal: 6001. 


\title{
UMA ANÁLISE DOS JOGOS DE NEGÓCIOS COMO ESTRATÉGIA DE ENSINO-APRENDIZAGEM À LUZ DO INTERACIONISMO PELO VIÉS DIALÉTICO
}

\section{RESUMO}

Tendo como sustentação, o interacionismo sujeito-objeto de Piaget no ensino-aprendizagem propiciado pela linha pedagógica predominante nos jogos de negócios dirigidos ao ensino de Administração, bem como a proposta de superação via interacionismo sujeito-social de Vygotsky, é que se estrutura o presente trabalho. Norteado pela dúvida sobre qual alternativa pedagógica incorporada à prática metodológica dos jogos de negócios permite avançar de um interacionismo sujeito-objeto para um interacionismo sujeitosocial, busca-se como objetivo principal nesse ensaio, apresentar uma alternativa pedagógica para os jogos de negócios que avance para além da perspectiva interacionista piagetiana na direção do interacionismo vygotskyano. Nesse sentido a metodologia adotada constitui-se de uma pesquisa bibliográfica, que discorre inicialmente sobre as características das principais tendências pedagógicas, partindo da tradicional até a histórico-crítica. Na sequencia destaca-se que os jogos em si, apresentam desdobramentos relacionados as tendências humanista e cognitivista apoiando-se na valorização dos interesses e ritmos individuais. Explicando a diferença entre os modelos piagetiano e vygotskyano que possibilitaria uma superação interacionista, é apresentado um detalhamento dos processos avaliativos para os jogos de negócios dentro de uma proposta pedagógica com pano de fundo dialético que reforça a dimensão social do conhecimento a partir da perspectiva histórico-critica de Saviani. A partir da analise do processo ensino-aprendizagem, destacando as diferenças das contribuições de Piaget e Vygotsky, conclui-se que os jogos podem avançar ao propor critérios avaliativos objetivos que pressupõe tomada de consciência por meio da zona de desenvolvimento proximal, caracterizada pela distância entre o nível de desenvolvimento real do indivíduo e seu nível de desenvolvimento potencial.

\section{Palavras-chave}

Pedagogia dos jogos, psicologia dos jogos, interacionismo nos jogos de negócios.

\section{AN ANALYSIS OF BUSINESS GAMES AS TEACHING AND LEARNING STRATEGY IN LIGHT OF THE BIAS INTERACTIONISM DIALECTICAL}

\begin{abstract}
With the support dialectical interactionism bias in the teaching-learning provided by the online educational games prevalent in the business directed to the teaching of Directors is that estutura this essay. Guided by the question about which alternative pedagogical methodology incorporated into the practice of business games lets go of a subject-object interactionism interactionism subject to a social-search is the main objective in this essay, to provide an alternative educational games business that advances beyond Piaget's interactionist perspective toward the Vygotskyan interactionism. In this sense the methodology consisted of a literature search, which initially talks about the characteristics of the main pedagogical trends, from the traditional to the historical-critical. In the sequel we highlight that the games themselves, present developments related trends humanist and cognitive relying on the valuation of individual interests and rhythms. Explaining the difference between the models Piaget and Vygotsky would allow an overshoot interactionist, presents a detailed evaluation processes for the games business into an educational project with dialectical background that reinforces the social dimension of knowledge from the historical perspective criticizes Saviani. From the analysis of the teaching-learning process, highlighting the differences in the contributions of Piaget and Vygotsky, it is concluded that the games can advance the goals proposed evaluative criteria which presupposes awareness through the zone of proximal development, characterized by the distance between the actual developmental level of the individual and their level of development potential.
\end{abstract}

\section{Keywords}

Pedagogy of the games, psychology of games, games interactionism in business. 


\section{Introdução}

Os jogos de negócios tem sido um valioso recurso de ensino amplamente utilizado nos cursos de graduação, principalmente de administração (Stahl \& Lopes, 2004, p. 1). Tem-se observado pelas publicações a respeito, "[ ...] a satisfação de alunos e professores com a utilização de jogos de empresas enquanto técnica de ensino-aprendizagem" (Motta, Melo \& Paixão, 2009, p. 2). Porém, tem-se observado também, uma preocupação com a avaliação da aprendizagem quando da utilização dos jogos: "Como avaliar o aluno? Como Ihe atribuir uma nota?" (Stahl \& Lopes, 2004, p. 1).

Estudos realizados por Sauaia (2003) revelam inexistência da correlação entre conhecimento individualista e desempenho coletivo, apontando a necessidade de avançar para além da perspectiva interacionista sujeito-objeto (predominante nos jogos), indicando como apropriada a incorporação práticas avaliativas na perspectiva do interacionismo social.

Diante deste contexto, o presente artigo parte da seguinte questão: Qual a alternativa pedagógica que utilizada nos jogos de negócios pode avançar de um interacionismo sujeito-objeto para um interacionismo sujeito-social?

No intuito de responder este problema de pesquisa, elenca-se como objetivo geral do trabalho, apresentar uma alternativa pedagógica para os jogos de negócios que avance para além da perspectiva interacionista sujeito-objeto na direção do interacionismo social.

Como objetivos específicos, em primeiro lugar pretende-se identificar quais são as tendências pedagógicas predominantes nos jogos de negócios e em segundo lugar, busca-se apontar uma sugestão de pedagogia de forma detalhada, que possa contribuir para a superação da perspectiva interacionista sujeitoobjeto, melhorando as práticas avaliativas ao se trabalhar com jogos de negócios.

No intuito de alcançar o objetivo do presente estudo a fim de responder a questão central, organizou-se o trabalho em quatro partes distintas, sendo que na primeira parte, denominada "tendências pedagógicas", apresentam-se as tendências pedagógicas que surgiram ao longo da história, cada qual com as suas respectivas características, em função do fim a que se propõe. Na segunda parte, realiza-se uma análise dos jogos, na forma como são trabalhados atualmente, apontando a predominância das tendências humanistas e cognitivas.

Na sequencia, a terceira parte do ensaio aponta diferenças entre a atual forma de trabalho com os jogos e a nova proposta que permite o avanço para um modelo que coloque o sujeito em um nível maior de relação com o social. Por fim, antes das considerações finais, dedica-se uma parte do conteúdo para detalhar uma proposta de avaliação dos jogos numa perspectiva dialética que pode favorecer as relações do sujeito com o social, a partir da perspectiva histórico-critica de Saviani.

\section{Tendências Pedagógicas}

Cada tendência pedagógica está imbuída de intencionalidades políticas, econômicas, sociais, culturais, ou seja, tem a sua devida importância de acordo com as necessidades e expectativas de um determinado grupo, em seu contexto histórico. Por exemplo, no contexto jesuítico no qual se pretendia maior disciplina e transmissão das doutrinas e conteúdos clássicos, a forma tradicional de ensino apresentava-se como adequada em função de permitir o alcance dos objetivos propostos.

Em contrapartida, num período de urbanização, no qual prevalece o discurso democrático, surge a perspectiva cognitivista, na qual com os avanços da psicologia são valorizados os ritmos e interesses individuais, predomina o método experimental e busca-se a compreensão de como a aprendizagem ocorre.

No contexto da ditadura militar, inicia-se uma tendência de programas instrucionais, prevalece o condicionamento através do reforço, valoriza-se o recurso audiovisual, o currículo é elaborado por um grupo de especialistas, sendo meramente executado pelos professores.

Nesse sentido observa-se ao longo da história, o surgimento de várias tendências pedagógicas, cada qual com as suas respectivas características, em função do fim a que se propõe. No tópico a seguir são apresentadas e discutidas as características centrais das principais tendências, bem como alguns apontamentos sobre como ocorre o processo de avaliação em cada perspectiva, a fim de que, na sequência do trabalho, seja possível identificar os limites e as possibilidades da incorporação dessas premissas na metodologia de aprendizado propiciada pela utilização dos jogos de negócios como estratégia de ensino, especialmente nos cursos de administração. 


\subsection{Tradicional}

A pedagogia tradicional privilegia os aspectos cognitivos, desprezando as diferenças sociais, afetivas e culturais. A resolução dos problemas ocorre por partes e as dificuldades são graduadas de acordo com sua complexidade, ou seja, vão do mais simples ao mais complexo.

Os alunos devem reter conhecimento, por meio da memorização, seguindo modelos convencionais (clássicos), generalizando-os para novas aplicações.

A coação é o caminho mais eficiente para a aprendizagem, assim como a premiação baseada em critérios quantitativos e classificatórios.

Neste modelo o professor querendo "ganhar tempo", "dá" logo o resultado, a síntese, a conclusão, o modelo, a fórmula, o algoritmo "[ ...] Dessa forma, deixa de lado a preocupação com o tempo de reflexão necessário para a reapropriação do conhecimento pelo educando, bem como com a fundamentação e significação" (Vasconcellos, 2005, p. 30).

O aluno passa a repetir a resolução do problema sem a compreensão do seu significado teóricoprático. "Trata-se assim, de uma atividade mecânica, desprovida de sentido, já que o significado do conhecimento, sua vinculação com a realidade não é trabalhada" (Vasconcellos, 2005, p. 27).

A metodologia oferta o mesmo caminho para todos, através de aulas expositivas, que privilegiam as camadas mais favorecidas, exigindo esforço individual. A competição é estimulada e os resultados são mais importantes do que o processo. "Pode-se afirmar que as tendências englobadas por esse tipo de abordagem possuem uma visão individualista do processo educacional, não possibilitando, na maioria das vezes, trabalhos de cooperação [ ...]" (Mizukami, 1986, p. 10).

“Mede-se, portanto, pela quantidade e exatidão de informações que se consegue reproduzir. Daí a consideração de provas, exames, chamadas orais, exercícios, etc., que evidenciem a exatidão da reprodução da informação“ (Mizukami, 1986, p. 17). Neste contexto, a avaliação se dá pela mensuração da aquisição do patrimônio cultural.

\subsection{Cognitivista}

$\mathrm{Na}$ pedagogia cognitivista o aluno tem um papel ativo, participando das experiências de aprendizagem. Há uma valorização do processo de construção do conhecimento sendo considerados os aspectos psicológicos (ritmos, interesses individuais). "Embora se note preocupação com relações sociais, a ênfase dada é na capacidade do aluno de integrar informações e processá-las." (Mizukami, 1986, p. 59).

A avaliação é processual, sendo o erro considerado construtivo e continuamente passível de superação. A descoberta é hiper-valorizada e privilegia-se a autonomia no aprendizado.

Neste contexto a avaliação é subjetiva e considera os avanços individuais, pressupondo metas pessoais.

Uma das formas de se verificar o rendimento é através de reproduções livres, com expressões próprias, relacionamentos, reprodução sob diferentes formas e ângulos, explicações práticas, explicações causais etc. O controle do aproveitamento deve ser apoiado em múltiplos critérios, considerando-se principalmente a assimilação e a aplicação em situações variadas (Mizukami, 1986, p. 83).

\subsection{Humanista}

Na pedagogia humanista, o indivíduo tem liberdade e responsabilidade de escolha no processo de ensino-aprendizagem. "O 'ensino é centrado no aluno'" (Mizukami, 1986, p. 37).

Neste contexto, o estudante pode selecionar conteúdos que considera relevantes para a sua vida. “O professor em si não transmite conteúdo, dá assistência, sendo um facilitador da aprendizagem. O conteúdo advém das próprias experiências dos alunos." (Mizukami, 1986, p. 38).

A proposta de Neill (1963) defende a educação através do autogoverno e da auto regulação do aluno, cabendo ao professor, estimular o pensamento e não incutir doutrinas. Neste sentido, o aluno faz o que quer, respeitando regras estabelecidas em assembleias de estudantes. Neste sentido Rogers defende a responsabilidade pelas formas de controle da aprendizagem, via auto avaliação: 
Há, dentro da pessoa humana, base orgânica para um processo organizado de avaliação (capacidade do organismo de reorganizar-se constante e progressivamente a partir do feed back recebido) (Rogers, 1972, p.142). A avaliação de cada um de sua própria aprendizagem auto iniciada se torna aprendizagem responsável (Rogers, 1972 , p. 235-236).

\subsection{Comportamentalista}

Esta pedagogia é caracterizada pelo tecnicismo e valoriza a experiência ou a experimentação planejada como a base do conhecimento. Desta forma, pressupõe a necessidade de pré-requisitos para a possibilidade de avanços. Os recursos são supervalorizados na perspectiva do ensino como processo de condicionamento/reforço da resposta que se quer obter. A ênfase está na instrução programada com etapas nas quais se podem constatar comportamentos observáveis e mensuráveis.

Neste sentido, os modelos são desenvolvidos a partir da análise dos processos por meio dos quais o comportamento humano é modelado e reforçado.

O que nós queremos conhecer no caso de muitos termos psicológicos tradicionais é primeiro as condições estimuladoras específicas sob as quais eles são emitidos (isto corresponde a 'encontrar os referentes') e, segundo, (e esta é uma questão sistemática muito mais importante), por que cada resposta é controlada por sua condição correspondente (Skinner, 1957, p. 419).

Segundo Mizukami, a avaliação está diretamente vinculada aos objetivos intermediários e finais, fornecendo dados para o arranjo de reforços necessários para os próximos comportamentos a serem modelados.

Decorrente do pressuposto de que o aluno progride em seu ritmo próprio, em pequenos passos, sem cometer erros, a avaliação consiste, nesta abordagem, em se constatar se o aluno aprendeu e atingiu os objetivos propostos quando o programa foi conduzido até o final de forma adequada [ ...] se procura, através de uma prétestagem, conhecer os comportamentos prévios, a partir dos quais serão planejadas e executadas as etapas seguintes do processo de ensino-aprendizagem. [ ...] A avaliação também ocorre no final do processo, com a finalidade de se conhecer se os comportamentos finais desejados foram adquiridos pelos alunos (Mizukami, 1986, p. 34-35).

Percebe-se assim nesta concepção pedagógica, a valorização do produto em detrimento ao processo, sendo considerado o aluno em particular, através da individualização do ensino. Para tanto, são utilizadas técnicas refinadas de controle que pressupõe a modelação do comportamento.

\subsection{Libertadora}

A pedagogia libertadora enfatiza o diálogo e a consciência diante da problematização da realidade, no intuito de formar um indivíduo autenticamente autônomo.

Saber que devo respeito à autonomia, à dignidade e à identidade do educando e, na prática, procurar a coerência com este saber, me leva inapelavelmente à criação de algumas virtudes ou qualidades sem as quais aquele saber vira inautêntico, palavreado vazio e inoperante. De nada serve, a não ser para irritar o educando e desmoralizar o discurso hipócrita do educador, falar em democracia e liberdade mas, impor ao educando a vontade arrogante do mestre (Freire, 1996, p. 62).

Neste sentido, educador e educando são sujeitos na construção do conhecimento e consideram as variáveis do meio cultural, visando a sua transformação. Freire considera que no diálogo "se aprende ensinando e se ensina aprendendo", o que consiste em contínua interação e exercício de cidadania. No processo dialógico, são oportunizadas, segundo Mizukami (1986, p. 99) “a cooperação, a união, a organização, a solução em comum dos problemas".

A avaliação brota da prática educativa oriunda do relacionamento entre aluno e professor ocorrendo uma mútua auto avaliação na qual tanto professores quanto alunos reconhecem suas dificuldades e seus progressos. "A avaliação é da prática educativa, e não de um pedaço dela" (Freire, 1982, p. 94).

\subsection{Histórico-Crítica}

A pedagogia histórico-crítica traduz uma concepção de interdisciplinaridade que, para além da justaposição das disciplinas, busca o entendimento sobre a articulação das partes, bem como das conexões 
teóricas e práticas que vão constituir a totalidade na produção do conhecimento em suas diversas dimensões.

Este modelo pedagógico é apresentado por Dermeval Saviani e busca democratizar o saber científico historicamente acumulado, através de métodos de ensino que pressupõem a vinculação entre sociedade e educação numa perspectiva dialética, marcadamente política e revolucionária, que visa "transformar as relações de produção que impedem a construção de uma sociedade igualitária". (Saviani, 2007, p. 76)

Para conquistar esta transformação, Saviani (2007, p. 77) afirma que a educação supõe "a desigualdade no ponto de partida e a igualdade no ponto de chegada". Nesta perspectiva seus métodos devem superar os tradicionais e novos, incorporando as contribuições de ambos, de forma, que:

Serão métodos que estimularão a atividade e iniciativa dos alunos, sem abrir mão, porém da iniciativa do professor; favorecerão o diálogo dos alunos entre si e com o professor, mas sem deixar de valorizar o diálogo com a cultura acumulada historicamente; levarão em conta os interesses dos alunos, os ritmos de aprendizagem e o desenvolvimento psicológico, mas sem perder de vista a sistematização lógica dos conhecimentos, sua ordenação e gradação para efeitos do processo de transmissão-assimilação dos conteúdos cognitivos (Saviani, 2007, p. 69).

Entre a prática social inicial e final existem momentos articulados, que formam o que Gasparin (2005, p. 9) chama de "teorização metodológica do processo de desdobramento e análise do conteúdo escolar": a problematização, a instrumentalização, e a catarse.

A catarse seria o momento avaliativo no qual, ainda que de forma provisória, é chegado o momento em que o aluno deve revelar a compreensão acerca de todo o processo de trabalho, bem como a passagem da síncrese à síntese:

Trata-se de uma nova postura mental do aluno, que deve ser capaz, neste momento de reunir intelectualmente o cotidiano e o científico, o teórico e o prático, demonstrando através da avaliação, o quanto se aproximou da solução das questões levantadas e trabalhadas nas fases anteriores do processo pedagógico (Gasparin, 2005, p. 10).

Os instrumentos de avaliação podem ser informais, nos quais "o aluno escolhe o modo de expressão através do qual se sinta mais seguro para manifestar seu nível de aprendizagem" e formais nos quais se destaca que:

O professor pode propor verificações orais, debates, seminários, resumos; elaboração de textos, redações, confecção de materiais como cartazes, maquetes ou objetos específicos conforme o conteúdo trabalhado; dramatizações; provas escritas do tipo dissertativo, objetivo, subjetivo; auto-avaliação, realização de experiências e outras formas que expressem o grau de aprendizagem alcançado (Gasparin, 2005, p. 137).

\section{Os Jogos e o Predomínio das Tendências Humanista e Cognitivista}

Os jogos começam a ser valorizados no contexto educacional brasileiro a partir do Manifesto dos Pioneiros da Educação Nova, que ocorreu em meio ao processo de reordenação política resultante da Revolução de 30, consolidado pela visão de um segmento da elite intelectual que vislumbrava possibilidades de influenciar a organização da sociedade brasileira através da educação. O Movimento organizou-se e fortaleceu-se através de 26 intelectuais, entre os quais Anísio Teixeira, Antônio Ferreira de Almeida Júnior, Fernando de Azevedo, Afrânio Peixoto, Lourenço Filho, Roquette Pinto, Delgado de Carvalho, Hermes Lima e Cecília Meireles.

O documento configurou-se como marco inaugural do projeto de renovação educacional do país ao constatar a desorganização do aparelho escolar, e propor que o Estado organizasse um plano geral de educação através da bandeira da escola única, pública, laica, obrigatória e gratuita. A proposta, embora liberal, foi considerada reformadora, por revelar-se em oposição à escola existente, chamada de "tradicional".

O referido manifesto, ocorrido no ano de 1932, apoiou-se em diversas abordagens psicológicas, que valorizavam os interesses e ritmos individuais, o processo do aprender a aprender, o método empírico, no qual se aprende pela experiência, sendo o processo de descoberta a chave para o conhecimento.

Esta perspectiva escolanovista (humanista e cognitivista), desdobrou-se em duas tendências pedagógicas: a humanista e a cognitivista. Em ambas os jogos são referência na atividade educacional, sendo reconhecidas suas contribuições. 
Os artigos científicos pesquisados neste trabalho, que tratam do referido assunto, trazem marcadamente estas duas tendências, como podemos observar: Motta, Quintella, Jahn \& Santos (2009) ao inferir que alguns conteúdos das aulas expositivas tradicionais são irrelevantes, apresenta uma reflexão sobre o fato de que, no jogo, o aluno ocupa a centralidade do processo de ensino-aprendizagem e, desta forma, aponta os jogos como uma solução para se chegar às habilidades necessárias ao futuro administrador.

Esta centralidade é analisada por Santos (2003, p. 86), quando "na abordagem humanista o enfoque é o sujeito, "ensino centrado no aluno'." Refere-se assim ao enfoque de Carl Rogers, que "enfatiza as relações interpessoais, objetivando o crescimento do indivíduo, nos seus processos internos de construção e organização pessoal da realidade, de forma a atuar como uma pessoa integrada". No mesmo contexto, autores como Motta, Melo \& Paixão (2009) enfatizam a satisfação de alunos e professores com a utilização dos jogos no processo de ensino-aprendizagem.

A escolha de se trabalhar com jogos de empresas é baseada em princípios da aprendizagem baseada em problemas (Ribeiro, 2005) ou PBL (do inglês, Problem-based Learning) e da aprendizagem vivencial (Kolb, 1984). Ambas apresentam uma proposta construtivista, ou seja, busca-se fugir do tradicionalismo, no qual o aluno tem o papel passivo de assistir à exposição do professor. A aplicação de jogos de empresas permite ao aluno buscar e manipular informações de acordo com os seus próprios interesses e percepções, assumindo o papel ativo no processo de ensino-aprendizagem e a responsabilidade pela construção do seu próprio conhecimento. Grosso modo, o aprendizado é entendido como a habilidade intelectual para enquadrar e resolver, com outros aprendizes envolvidos, problemas abertos de forma original, coordenando atividades complexas (Motta, Melo \& Paixão, 2009, p. 3).

Destaca-se aqui a proposta cognitivista ou construtivista, cujos principais pesquisadores foram o biólogo e filósofo suíço Jean Piaget e o norte-americano Jerome Bruner. Predomina o caráter interacionista entre sujeito e objeto, no qual:

o aprendizado é decorrente da assimilação do conhecimento pelo sujeito e também da modificação de estruturas mentais já existentes [ ...] valorizam-se as tentativas experimentais, a pesquisa, a descoberta, o estudo do meio natural e social, o método de solução de problemas (Santos, 2003, p. 86).

Outro aspecto a ser considerado nos artigos científicos publicados sobre os jogos no Brasil é o fato de que as contribuições pedagógicas referem-se à superação do modelo tradicional de ensino, marcadamente pela oposição escolanovista (humanista e cognitivista), visto que "Um primeiro aspecto que pode ser destacado na experiência é a ampla superioridade didático-pedagógica, percebida pelos participantes, do jogo de empresas relativamente a outros métodos tradicionais de ensino, como, por exemplo, aulas expositivas, estudo de casos e seminários" (Lopes, 2001a, p. 4).

Quanto à avaliação da implementação dos jogos, percebe-se um apelo a satisfação individual dos alunos como parâmetro para sua utilização em grande escala, pois "a aprendizagem cognitiva com satisfação, proporcionada pela abordagem vivencial dos jogos de empresas, identificada por Sauaia (2003), praticamente elimina as críticas relacionadas à eficácia do método e o credencia a ser utilizado em maior escala" (Lopes, 2001a, p. 4).

No entanto, pouco se percebe um aprofundamento da investigação sobre a eficácia dos resultados da aprendizagem no decorrer do processo, tendo como quase uma exceção dentre as publicações que pesquisamos, Stahl e Lopes (2004), que aponta como complexa, as características de uma boa avaliação quando se trabalha com os jogos:

Finalmente parece não haver dúvidas sobre as dificuldades de levar a cabo um processo de avaliação com as características discutidas neste estudo. Envolve empenho e planejamento por parte dos professores, além de tempo e trabalho para sua aplicação em diferentes momentos da atividade (Stahl \& Lopes, 2004, p. 13).

O professor tem um papel de animador, estimulador da aprendizagem e, mantendo o aspecto lúdico, busca resultados a partir do comportamento dos alunos. Não se detém tanto nos conteúdos, mas na forma como os alunos aprendem. Apesar de fugir do aspecto competitivo do jogo, esbarra-se nos critérios de desempenho que estão presentes nas análises dos resultados das empresas fictícias.

Também se verifica uma avaliação superior quando o animador consegue manter o aspecto lúdico e o resultado classificatório do jogo como dimensão secundária da atividade. [...] A condição de frustração nos grupos perdedores no SSE, quando ocorre, pode estar sendo mais acentuada, em função do critério de avaliação do desempenho presente no jogo (Lopes, 2001a, p. 5). 
A avaliação por tratar-se de uma perspectiva vivencial, portanto empírica, revela-se complexa. Assim, por mais que estudiosos se debrucem sobre o assunto, buscando articular objetivo a resultados, encontram-se termos que revelam a dificuldade para encontrar recursos de avaliação precisos e seguros, como podemos observar nesta avaliação da proposição teórica de Kolb, um dos defensores da aprendizagem vivencial do jogo.

Para uma adequada avaliação da aprendizagem, faz-se necessário considerar a abordagem da aprendizagem que suporta a atividade desenvolvida, particularmente os objetivos inerentes a ela, além dos objetivos específicos estabelecidos. A proposição teórica de Kolb (1978) sobre aprendizagem vivencial parece suportar conceitualmente a dinâmica cíclica tipicamente presente nos jogos de empresas gerais. (Stahl \& Lopes, 2004, p. 2, grifo nosso).

Esta referência é significativa, pois foi possível constatar nos artigos estudados para este trabalho, uma predominância de referências ao modelo de aprendizagem vivencial de Kolb. Ciente deste fato não se tem como objetivo questionar a eficácia deste modelo. Pretende-se apenas, apontar sua relação direta com a perspectiva cognitivista, onde a ênfase está no aluno e no processo.

Comecemos com um modelo de como as pessoas aprendem o chamado modelo de aprendizagem vivencial. O modelo é rotulado de "vivencial" por dois motivos. O primeiro é histórico, vinculado a suas origens intelectuais na psicologia social de Kurt Lewin dos anos 40 e ao trabalho de treinamento da sensibilidade e de ensino em laboratório dos anos 50 e 60 . O segundo motivo é enfatizar o importante papel da experiência no processo de aprendizagem, ênfase essa que diferencia essa abordagem de outras teorias cognitivas do processo de aprendizagem. O cerne do modelo é uma descrição simples do ciclo de aprendizagem - como a experiência se traduz em conceitos, os quais, por sua vez, são usados como guias na escolha de novas experiências (Kolb, 1997, p. 323).

Tendo como entendimento a predominância da tendência cognitivista quando se trabalha com os jogos, na forma como vem sendo proposta até então, cabe avaliar o aluno pelos métodos inerentes a essa prática pedagógica:

A avaliação cognitivista consiste basicamente na observação dos professores sobre o processo de aprendizagem de seus alunos, ou até da própria auto avaliação dos alunos, numa perspectiva diagnóstica e formativa, tendo em vista as necessidades individuais de cada grupo. Neste processo são valorizados critérios subjetivos, de difícil mensuração, tais como: participação, aptidão especial, personalidade, interesse, curiosidade, criatividade, desempenho em sala de aula durante a execução dos trabalhos, entre outros.

Neste sentido, embora se alegue que a avaliação tem por objetivo diagnosticar a ocorrência e a não ocorrência de aprendizagem, para fins de replanejamento do trabalho pedagógico, pode ocorrer em alguns casos a rotulação de acordo com o comportamento apresentado, o que pode resultar no afastamento do aluno da escola. Outro agravante acaba sendo a possibilidade de esvaziamento de conteúdo, por tratar-se de um currículo extremamente flexível, bem como o equívoco de se considerar que neste processo o erro ao ser "construtivo" não pode ser corrigido.

\section{Os Jogos na Perspectiva Interacionista: Diferenças do Modelo Piagetiano para o Modelo Vygotskyano}

Como apresentado na seção anterior, os jogos de negócios atualmente no Brasil, se caracterizam pedagogicamente pela predominância das tendências humanistas e cognitivistas. Nesta seção, busca-se um paralelo entre Piaget e Vygotsky nos jogos, a fim de apontar diferenças entre o interacionismo de um e de outro.

Observa-se nas publicações sobre Jogos de Empresas, uma perspectiva interacionista, o que fica claro em Santos (2003)

Desta forma, o ensino deve visar ao desenvolvimento da inteligência através do "construtivismo interacionista", que, em essência, parte do princípio de que o que é assimilado o é a uma estrutura mental anterior, criando uma nova estrutura em seguida. Neste sentido, a concepção piagetiana implica a interdependência do homem em relação ao meio em que vive a sociedade, sua cultura, seus valores e seus objetos (Santos, 2003, p. 86). 
Para a leitura destas referências ao interacionismo, entende-se como relevante, as considerações acerca do interacionismo de Piaget que considera o meio no qual o sujeito está inserido, porém de certa forma desconsidera fatores socioculturais.

De modo bastante geral, são encontradas críticas ao interacionismo piagetiano principalmente no que se refere à influência dos fatores socioculturais na formação da consciência, do pensamento humano. [..] Embora Piaget tenha enfatizado a importância do meio nos processos de desenvolvimento cognitivo, detendo-se na contribuição do sujeito nas suas trocas com o meio, deixou de lado a relação inversa, possível e necessária, que é a contribuição do meio na estruturação da consciência (Scalcon, 2002, p. 42-43)

A perspectiva interacionista também aparece em outras publicações sobre jogos, porém na perspectiva vygotskyana, como por exemplo, em Lopes (2001b):

Em seus estudos, Vygotsky buscou explicar o desenvolvimento do homem, distintivamente dos demais seres da natureza, a partir do desenvolvimento das chamadas funções psicológicas superiores como a memória, a percepção, o pensamento e a linguagem, ou seja, a passagem do ser biológico ao ser cultural (Lopes, $2001 \mathrm{~b}, \mathrm{p}$. 48).

Percebe-se aí uma diferenciação entre Piaget e Vygotsky onde, o primeiro em suas pesquisas está preocupado com as questões biológicas da evolução cognitiva do indivíduo.

Para explicar essa transformação, Vygotsky considerou a maturação em si como um fator secundário no desenvolvimento das formas complexas de comportamento. Segundo ele, o desenvolvimento cultural é um processo de origem necessariamente social, jamais individual, como entendia a Psicologia de sua época. As funções superiores ou culturais, antes de se constituírem no plano pessoal já existem no plano social ou interpessoal (Lopes, 2001b, p. 48).

Neste ponto, quando Vygotsky trata o desenvolvimento como um processo necessariamente social, pode-se começar a entender como o interacionismo de Vygotsky está relacionado com o meio social, numa "via de mão dupla" e não apenas com o ambiente, numa "via de mão única" que caracteriza o interacionismo de Piaget.

Tais concepções levam à ideia fundamental da teoria de Vygotsky que é o conceito da zona de desenvolvimento proximal, caracterizada pela distância entre o nível de desenvolvimento real do indivíduo e o nível de desenvolvimento potencial. O primeiro significando a capacidade de realizar tarefas de forma independente ou referindo-se a etapas já alcançadas ou consolidadas do desenvolvimento. O segundo representando a capacidade de desempenhar determinadas tarefas com auxílio de demonstrações, instruções e assistência durante o processo, ou seja, com apoio de outra pessoa ou interagindo com outras pessoas (Oliveira, 1993). Segundo Oliveira, o nível de desenvolvimento potencial, como um limite superior da zona de desenvolvimento proximal, até o qual é possível alteração do desenvolvimento de uma pessoa pela interferência de outra é conceito fundamental na teoria de Vygotsky. Daí decorre a importância das interações com os professores e outros participantes do processo de ensino aprendizagem (Lopes, 2001b, p. 48-49).

Percebe-se, portanto, uma diferenciação entre o interacionismo de Piaget e o interacionismo de Vygotsky, pois Piaget trata a interação com o ambiente e valoriza "como o aluno aprende", numa perspectiva individual de interação com o meio e Vygotsky retoma a importância do "ensino" para o processo de aprendizagem, valoriza o papel do professor como mediador e enfatiza a interação com o meio social, ou seja, a influência do grupo (adultos e alunos) para a apropriação do conhecimento.

O objetivo deste trabalho não é aprofundar a diferenciação das propostas interacionistas de Piaget e de Vygotsky, mas sim, conforme especificado na introdução, apresentar uma proposta interacionista que supere a relação sujeito-objeto, entendendo que o interacionismo de Vygotsky proporciona uma melhor relação do sujeito com o social ao passo que o interacionismo de Piaget favorece a relação do sujeito com o objeto. Neste sentido, partindo das perspectivas apontadas por autores de Jogos de Negócios, entende-se que

[ ...] considera-se indispensável uma abordagem séria e abrangente de avaliação em jogos de empresas para que se possa potencializar a ferramenta como técnica de ensino-aprendizagem e se possa tirar dela o melhor proveito em favor de uma formação profissional de qualidade superior (Stahl \& Lopes, 2004, p. 13).

Por isso, quando é feita a referência ao não aprofundamento nas diferenciações entre Piaget e Vygotsky, o mesmo não é feito com o intuito de furtar-se em fazer algumas comparações entre os dois autores no que for necessário para a compreensão deste trabalho. A intenção e sim, isentar-se de 
aprofundar as bases ideológicas, psicológicas, pedagógicas e didáticas de cada um, o que seria necessário para uma verdadeira comparação entre eles, mas que demandaria um trabalho de maior fôlego, o que não é a proposta neste momento. O que parece importante, é demonstrar que pode ser mais viável a abordagem no viés vygotskyano efetivamente, do que na perspectiva piagetiana, pensando no enfoque dos Jogos de Negócios.

Para clarear um pouco mais esta questão, na Figura 1 foi estabelecido um paralelo entre as duas linhas destacadas nesta discussão: a interacionista sujeito-objeto, referenciada em Piaget, e a interacionista sujeito-social, pautada em Vygotsky. Destaca-se nesta Figura 1, os autores que referenciam a proposta interacionista sujeito-social, no sentido do que constitui sua base ideológica, psicológica, pedagógica e didática, em contraposição à linha interacionista sujeito-objeto que, praticamente, resume-se ao referencial piagetiano, em que se destacam apenas as bases psicológica pautadas no próprio Piaget.

Figura 1: Composição da Linha Vygotskyana

\begin{tabular}{|c|c|}
\hline \multicolumn{2}{|c|}{ Linha Vygotskyana } \\
\hline Ideologia & Marx \\
\hline Psicologia & Vygostky \\
\hline Pedagogia & Saviani \\
\hline Didática & Gasparin \\
\hline
\end{tabular}

Fonte: Elaborado pelos autores

A fim de evitar confusões teóricas a cerca de termos bastante comuns como sociointeracinismo, construtivismo e interacionismo utilizados neste trabalho, elaborou-se a Figura 2 a seguir, onde encontrase a hierarquização contida no sociointeracionismo entre esses termos.

Figura 2: Hierarquia Sóciointeracionista

\begin{tabular}{|c|c|c|}
\hline \multicolumn{3}{|c|}{ Sóciointeracionismo } \\
\hline $\begin{array}{c}\text { Interacionismo Sujeito- } \\
\text { Objeto }\end{array}$ & $\begin{array}{c}\text { Interacionismo Sujeito- } \\
\text { Social }\end{array}$ & $\begin{array}{c}\text { Outras formas de } \\
\text { Interacionismo }\end{array}$ \\
\hline Piaget & Vygotsky & Outros autores \\
\hline
\end{tabular}

Elaborado pelos autores

Entende-se, portanto que o termo sociointeracionismo, engloba Piaget, Vygotsky e outros autores. Por esse motivo, este trabalho refere-se aos paralelos entre interacionismo sujeito-obejto e interacionismo sujeito-social, próprios de Piaget e Vygotsky respectivamente.

Entende-se ainda, que Piaget, muito conhecido pelo construtivismo, ou construtivismo piagetiano, está incluído na referência interacionismo sujeito-objeto.

O interacionismo vygotskyano, com suas bases marxistas, pode contribuir para o processo de ensinoaprendizagem, apontando novas possibilidades de avaliação na perspectiva dialética, cujo movimento síncrese-análise-síntese, traduz:

a) Síncrese: o conhecimento concreto, empírico, falho ou distorcido;

b) Análise: as problematizações, teorizações, abstrações e reflexões;

c) Síntese: o novo conhecimento sistematizado, articulado, compreendido em suas múltiplas dimensões.

\section{A Avaliação da Aprendizagem (Catarse), Numa Perspectiva Dialética dentro do Modelo Vygotskyano}

Discutido anteriormente algumas diferenças entre o interacionismo piagetiano e o interacionismo vygotskyano, prossegue-se nessa seção, apresentando como ponto central, uma proposta de avaliação da aprendizagem numa perspectiva dialética, fazendo-se necessário inclusive em alguns momentos estabelecer referências paralelas ao modelo piagetiano a fim de enfatizar o que está se propondo superar.

Ao explicar as chamadas operações superiores, Vygotsky utiliza o conceito de mediação, no qual a relação do sujeito com o mundo é mediada por sistemas simbólicos (instrumentos e símbolos). "A invenção e o uso de signos como meios auxiliares para solucionar um dado problema psicológico (lembrar, comparar coisas, relatar, escolher, etc) é análoga à invenção e uso de instrumentos, só que agora no campo psicológico" (Vygotsky, 1991, p.59). 
Este autor discorda de Piaget ao afirmar que “a aprendizagem pode ir não só atrás do desenvolvimento, não só passo a passo com ele, mas pode superá-lo, projetando-o para frente e suscitando nele novas formações" (Vygotsky, 2001, p. 304).

Neste contexto o papel do professor é desafiar o nível em que o aluno se encontra, almejando desenvolver seu potencial de aprendizagem, através da socialização das experiências culturais acumuladas historicamente pela humanidade. Neste sentido "só é boa aquela aprendizagem que passa a frente do desenvolvimento e o conduz" (Vygotsky 2001, p. 332).

Um conceito significativo dentro desta teoria por apresentar dimensão prospectiva, voltada para o futuro, para o trabalho cooperativo e para a valorização da imitação no contexto social é a zona de desenvolvimento proximal, que é

a distância entre o nível de desenvolvimento real, que se costuma determinar através da solução independente de problemas, e o nível de desenvolvimento potencial, determinado através da solução de problemas sob a orientação de um adulto ou em colaboração com companheiros mais capazes (Vygotsky, 1991, p. 97).

Na abordagem preliminar realizada no inicio do presente ensaio quanto a tendência Histórico-Crítica também se destacou elementos relacionados a pedagogia de Gasparin que procura alinhar os pressupostos psicológicos de Vygotsky com as perspectivas sociais de Saviani pautados na ideologia marxista.

Procura-se assim entender um pouco mais os passos dessa pedagogia, principalmente da catarse que consiste no processo de avaliação da pedagogia Histórico-Crítica cujos fundamentos psicológicos estão em Vygotsky.

Antes, porém de falar sobre catarse, é necessário entender que Saviani (2007), autor da pedagogia histórico-critica, visa superar a pedagogia tradicional e as pedagogias escolanovistas (humanista e cognitivista). Para tanto, é preciso ter um entendimento sobre o método dialético proposto pela pedagogia histórico-crítica, a fim de situar a catarse neste movimento articulado.

Para Saviani, nas outras pedagogias, o professor e o aluno são tratados de forma individual, sendo que nesta pedagogia por ele proposta, considera-se sobretudo as contribuições de ambos como agentes sociais.

Os métodos tradicionais assim como os novos implicam uma autonomização da pedagogia em relação à sociedade. Os métodos que preconizo mantêm continuamente presente a vinculação entre educação e sociedade. Enquanto no primeiro caso professor e alunos são sempre considerados em termos individuais, no segundo caso, professores e alunos são tomados como agentes sociais (Saviani, 2007, p. 70).

Neste sentido, esboça-se a seguir os passos da pedagogia histórico-crítica enquanto articuladores dos conhecimentos científicos frente às perspectivas sociais em suas necessidades e demandas, bem como o emprego dos jogos neste contexto.

\subsection{Prática Social Inicial}

No início do processo, o professor detém o conhecimento científico, mas desconhece o nível de capacidade de apropriação de seus alunos por desconhecer o contexto social no qual eles estão inseridos. Assim como os alunos, podem deter parte do conhecimento a ser estudado, porém não o fazem de forma sistematizada pedagogicamente.

E do ponto de vista pedagógico há uma diferença essencial que não pode ser perdida de vista: o professor, de um lado, e os alunos, de outro, encontram-se em níveis diferentes de compreensão (conhecimento e experiência) da prática social (Saviani, 2007, p. 70).

Na prática, em jogos de negócio, esta seria a situação em que o professor está com o jogo todo parametrizado para assim iniciar a atividade mediante a explicação metodológica e didática da abordagem. Para tanto é comum a organização dos participantes em grupos menores, tendo como conteúdo inicial a sensibilização quanto ao que se convencionou chamar de plano estratégico de cada equipe. Na sequencia abordagens explicativas e ao mesmo tempo de diagnóstico junto ao grupo permite que o professor que conduz a aplicação da atividade didática do jogo à realização de um rápido diagnóstico que permite sempre a percepção quanto ao nível de entendimento dos alunos quanto aos conceitos implícitos no jogo. Geralmente observa-se perfis e nível de entendimento variados a respeito do processo. 


\subsection{Problematização}

A partir do momento em que se percebe a necessidade de conhecimentos para prosseguir no jogo, estamos diante da problematização. Segundo Saviani (2007, p. 71), trata-se de detectar que questões precisam ser resolvidas no âmbito da prática social e, em consequência, que conhecimento é necessário dominar.

O professor em contrapartida deixa de ter um papel meramente de animador (como na escola nova) e passa a desempenhar um importante papel como mediador no processo ensino-aprendizagem. Desta forma, durante o jogo, deverá ter a percepção se o aluno também se deu conta da necessidade de conhecimentos, ou seja, percebe que lhe faltam conteúdos para prosseguir de forma consciente, a fim de evitar que o aluno insista em continuar com o jogo arriscando palpites de forma aleatória.

Pode ocorrer também que sejam necessárias algumas rodadas para que os alunos carentes de conteúdos para as decisões se deem conta dessa necessidade.

\subsection{Instrumentalização}

Diante dos problemas a serem resolvidos, e a identificação da necessidade de conhecimentos para resolvê-los, o professor deve orientar o aluno em como buscar estes conhecimentos ou ainda, apresentálos aos alunos de forma direta.

Trata-se de se apropriar dos instrumentos teóricos e práticos necessários ao equacionamento dos problemas detectados na prática social. Como tais instrumentos são produzidos socialmente e preservados historicamente, a sua apropriação pelos alunos está na dependência de sua transmissão direta ou indireta por parte do professor. (Saviani, 2007, p. 71).

Nesta etapa da instrumentalização, fazem-se necessárias atividades paralelas ao jogo que permitam aos alunos, acesso a conteúdos previamente definidos e estipulados como necessários à formação do educando.

\subsection{Catarse}

Para Saviani (2007, p. 72), catarse, trata-se da efetiva incorporação dos instrumentos culturais, transformados agora em elementos ativos de transformação social. Pode-se dizer que seria a forma como o aluno visualiza a sua nova atuação no jogo, em uma próxima rodada.

Essa nova visão estaria agora, subsidiada por conhecimentos adquiridos a partir da problematização e instrumentalização pela qual ele passou. Ele consegue agora, se posicionar de maneira mais consciente, ou seja, consegue se posicionar de forma diferente frente às mesmas situações.

Na prática, essa etapa poderia ocorrer em uma pausa, entre uma rodada e outra, ou ao final do jogo, e teria como finalidade que o aluno traduzisse, de forma oral ou escrita, a compreensão que teve acerca do processo de trabalho. Como salienta Gasparin (2005, p. 137), poderia ser um instrumento de avaliação na forma de:

[...] debates, seminários, resumos; elaboração de textos, redações, confecção de materiais como cartazes, maquetes ou objetos específicos conforme o conteúdo trabalhado; dramatizações; provas escritas do tipo dissertativo, objetivo, subjetivo; auto avaliação, realização de experiências e outras formas que expressem o grau de aprendizagem alcançado.

Tratar-se-ia do momento no qual o aluno demonstraria ter passado de um conhecimento sincrético (fragmentado/distorcido) para um conhecimento sintético (articulado/sistematizado):

Agora ele traduz oralmente ou por escrito a compreensão que teve de todo o processo de trabalho. Expressa sua nova maneira de ver o conteúdo e a prática social. É capaz de entendê-los em um novo patamar, mais elevado, mais consistente e mais bem estruturado. Compreende, da mesma forma, com maior clareza, tanto a Problematização quanto a Instrumentalização (Gasparin, 2005, p. 128). 


\subsection{Prática Social Final}

Após a avaliação/catarse, a síntese do conteúdo feita pelo professor, é mais consistente, pois foi submetida ao processo no qual a relação com o aluno e com a conjuntura social que o cerca influenciou na sua formação. O aluno também passa a ter melhores condições de convívio social, pois sistematiza melhor os conteúdos científicos através das diversas formas de linguagens.

O ponto de chegada é a própria prática social, compreendida agora não mais em termos sincréticos pelos alunos. Neste ponto, ao mesmo tempo em que os alunos ascendem ao nível sintético em que, por suposto, já se encontrava o professor no ponto de partida, reduz-se a precariedade da síntese do professor, cuja compreensão se torna mais e mais orgânica (Saviani, 2007, p. 72).

Portanto, a prática social final do aluno, agora subsidiado com novos recursos, faz com que ele tenha melhores condições se posicionar perante a sociedade. Na sequencia, a Figura 3 destaca o movimento dialético entre prática-teoria-prática indicando a relação com os níveis de desenvolvimento de Vygotsky e os passos de Saviani e Gasparin.

\begin{tabular}{|c|c|c|c|}
\hline Dialética & Prática & Teoria & Pratica \\
\hline Vygotsky & $\begin{array}{c}\text { Nível de Desenvolvimento } \\
\text { Potencial }\end{array}$ & $\begin{array}{c}\text { Zona de Desenvolvimento } \\
\text { Proximal }\end{array}$ & $\begin{array}{c}\text { Nível de Desenvolvimento } \\
\text { Real }\end{array}$ \\
\hline $\begin{array}{c}\text { Saviani e } \\
\text { Gasparin }\end{array}$ & Prática Social Inicial & $\begin{array}{c}\text { Problematização } \\
\text { Instrumentalização } \\
\text { Síntese }\end{array}$ & Prática Social Final \\
\hline
\end{tabular}

Figura 3: Relações entre Dialética, Vygotsky e Saviani/Gasparin

Elaborado pelos autores

\section{Considerações Finais}

O presente ensaio partiu do questionamento sobre qual alternativa pedagógica que utilizada nos jogos de negócios contribui avançando de um interacionismo sujeito-objeto para um interacionismo sujeitosocial. Nesse sentido elencou-se como objetivo geral do trabalho, apresentar uma alternativa pedagógica para os jogos de negócios que pudesse avançar para além da perspectiva interacionista sujeito-objeto na direção do interacionismo social. Articulando os conhecimentos das diferentes abordagens pedagógicas verificou-se que a proposta da pedagogia histórico-critica de Demerval Saviani, em consonância com o interacionismo de Vygotsky se mostrou atrativa para se trabalhar os jogos de negócios, contribuindo assim para uma relação sujeito-social. Na busca desta resposta, identificou-se que atualmente os jogos de negócios no Brasil, são orientados pedagogicamente pelas perspectivas Piagetianas onde são favorecidas as relações sujeito-objeto, identificação esta que cumpre com o primeiro objetivo específico do trabalho.

Atendendo ao segundo objetivo específico de apontar uma sugestão de pedagogia de forma detalhada, que possa contribuir para a superação da perspectiva interacionista sujeito-objeto, melhorando as práticas avaliativas ao se trabalhar com jogos de negócios, foram apresentados os passos da didática de Gasparin que atendem os pressupostos teóricos da pedagogia Histórico-crítica de Demerval Saviani.

Finalmente, considera-se que este trabalho não é conclusivo a ponto de propor uma nova pedagogia para trabalhar com jogos de negócios, a título de superação da forma como isso vem sendo feito atualmente. Entretanto, uma real possibilidade de futuras pesquisas a fim de caminhar na direção de outras vertentes comparativas seria conduzir um olhar à brasileira, ou seja, adotar a pedagogia genuína e brasileira - histórico crítica de Demerval Saviani - que no nosso ponto de vista, pode abrir outros horizontes para novas perspectivas de ensino-aprendizagem em administração.

\section{Referências}

Freire, P. (1982). Educação. O sonho impossível. In: Brandão, C. R. (Org.). Educador: Vida e Morte. Rio de Janeiro: Graal.

Freire, P. (1996). (34. ed.). Pedagogia da autonomia: Saberes necessários à prática educativa. São Paulo: Paz e Terra.

Gasparin, J. L. (2005). (3 ed.). Uma Didática para a pedagogia histórico-crítica. Campinas: Autores Associados. 
Kolb, D. A. (1997). A gestão e o processo de aprendizagem. In Starkey, K. Como as organizações aprendem: relatos dos sucessos das grandes empresas. São Paulo: Futura. pp. 321-341.

Lopes, P. C. (2001a). Jogos de empresas geral: a perspectiva do animador com a utilização na pósgraduação latu senso. Paper presented at the XXV Encontro da ANPAD, Campinas.

Lopes, P. C. (2001b). Formação de administradores: uma abordagem estrutural e técnico-didática. (Tese Doutorado), Universidade Federal de Santa Catarina, Florianópolis.

Mizukami, M. G. N. (1986). Ensino: as abordagens do processo. São Paulo: EPU.

Motta, G. S., Melo, D. R. A. \& Paixão, R. B. (2009). O Significado dos Jogos de Empresa no Processo de Aprendizagem em Administração: o discurso coletivo dos alunos. Paper presented at the XXXIII Encontro da ANPAD, São Paulo.

Motta, G. S., Quintella, R. H., Jahn, J. \& Santos, L. I. N. C. (2009). A Utilização de Jogo de Empresas nos Cursos de Graduação em Administração no Estado da Bahia. Paper presented at the XXXIII Encontro da ANPAD, São Paulo.

Neill, A. L. (1963). A Liberdade sem Medo. São Paulo: Ibrasa.

Rogers, C. (1972). Liberdade para Aprender. Belo Horizonte: Interlivros.

Santos, R. V. (2003). "Jogos de Empresas" Aplicados ao Processo de Ensino e Aprendizagem de Contabilidade. Revista Contabilidade \& Finanças, 31, p.78-95.

Sauaia, A. C. A. (2003). Conhecimento versus desempenho das organizações: um estudo empírico com jogos de empresas. Paper presented at the 70 Seminários em Administração, São Paulo.

Saviani, D. (2007). (39. ed.). Escola e democracia: Polêmicas do nosso tempo. Campinas: Autores Associados.

Scalcon, S. (2002). À procura da unidade psicopedagógica: articulando a psicologia histórico-cultural com a pedagogia histórico-crítica. Campinas: Autores Associados.

Skinner, B. F. (1957). Verbal Behavior. New York: Appleton-Century-Crofts.

Stahl, L. M.; Lopes, P. C. (2004). Estratégias de avaliação para jogos de empresas gerais: Avaliando desempenho ou aprendizagem. Paper presented at the XXVIII Encontro da ANPAD, Curitiba.

Vasconcellos, C. S. (2005). (16. ed.). Construção do conhecimento em sala de aula. São Paulo: Libertad.

Vygotsky, L. S. (1991). A formação social da mente, o desenvolvimento dos pocessos psicológicos superiores. São Paulo: Martins Fontes.

Vygotsky, L. S. (2001). A construção do pensamento e da linguagem. São Paulo: Martins Fontes. 